willing to devote time in developing their knowledge about diseases that have no surgical implications?

The second point is the feeling of the Gastroenterologist who is responsible for care and maintenance of the endoscopes. In our present set up, the expensive equipment is the prized item and not the patient or expertise [1]. As on today the Gastroenterologists are available even in some of the zonal hospitals but functioning endoscopes may, at times, be missing even in Command Hospitals. Many centres have only one functional endoscope. The functional efficiency (and hence the importance) of a Gastroenterologist goes down if his only endoscope becomes defunct. It is not unnatural if the Gastroenterologist is apprehensive about letting his equipment to be handled by any other person.

If the endoscopes are to be used by a general surgeon or a general physician, our organization needs to develop to a stage when the gastroenterology centres will have more than one endoscope, and the equipment will also available at the level of zonal hospitals.

Personally, if I am confident that the surgeon is motivated and will care for the equipment, and that he is not occupied enough by the surgical work, I will welcome him to use the scopes.

\section{Lt Col AC ANAND,vsM}

Reader,

Department of Medicine,

Armed Forces Medical College,

Pune 411040

\section{REFERENCE}

1. Anand AC. Going abroad: is it worthwhile? National Medical Journal of India 1996; 9: 185-6.

\title{
A NEW AURAL SWAB
}

\section{Dear Editor,}

We wish to share with other readers the results of a pilot study that was carried out at Amed Forces Medical College to assess the efficacy of a specially fabricated aural swab in microbiological diagnosis of 100 cases of chronic otitis media. Chronic otitis media is the commonest ear disease in our country and it is treated with a variety of systemic antibiotics and ear drops which may not be indicated in most cases. The key to diagnosing a microbial infection lies in the culture report on the sample of pus obtained from the ear. Frequently this is not possible with the conventional swab that is available in our laboratories as sampling from the middle ear or deep in the external auditory meatus is difficult. Hence, we fabricated a new swab and compared it with the conventional swab.

The conventional swab is made of a bamboo/broom stick which is $1-2 \mathrm{~mm}$ thick and a cotton bud which is 7-8 $\mathrm{mm}$ thick and is kept in a test tube of $12.6 \mathrm{~mm}$ diameter sealed at the top by a cotton plug (Fig 1). It is sterilised in a hot air oven at $160^{\circ} \mathrm{C}$ for 30 minutes.

The newly fabricated swab is made of chrome-coated spring steel material of 24 gauge $(0.7 \mathrm{~mm}$ thickness) and roughened at one end to grip the cotton. The cotton is wound tightly at this end so that the diameter at this end is $2 \mathrm{~mm}$. The other end is fitted into a rubber cork which is made of reusable, autoclavable material. The swab is autoclaved at $120^{\circ} \mathrm{C}$ under $15 \mathrm{lb}$ pressure for 30 minutes.

Hundred patients of chronic otitis media with actively discharging ears were selected for this study. The concha was cleaned with cotton, followed by actual sampling of the pus in the deep external auditory meatus. A sterile ear speculum was used and the area was visualised using the head mirror. Both the new swab and the conventional swab were used alternatively to obtain samples from the affected ear. A similar set of swabs were also used to take samples in the opposite ear which was either undiseased or nondischarging and acted as the control. All 4 swabs from cach patient was sent for culture and sensitivity test.

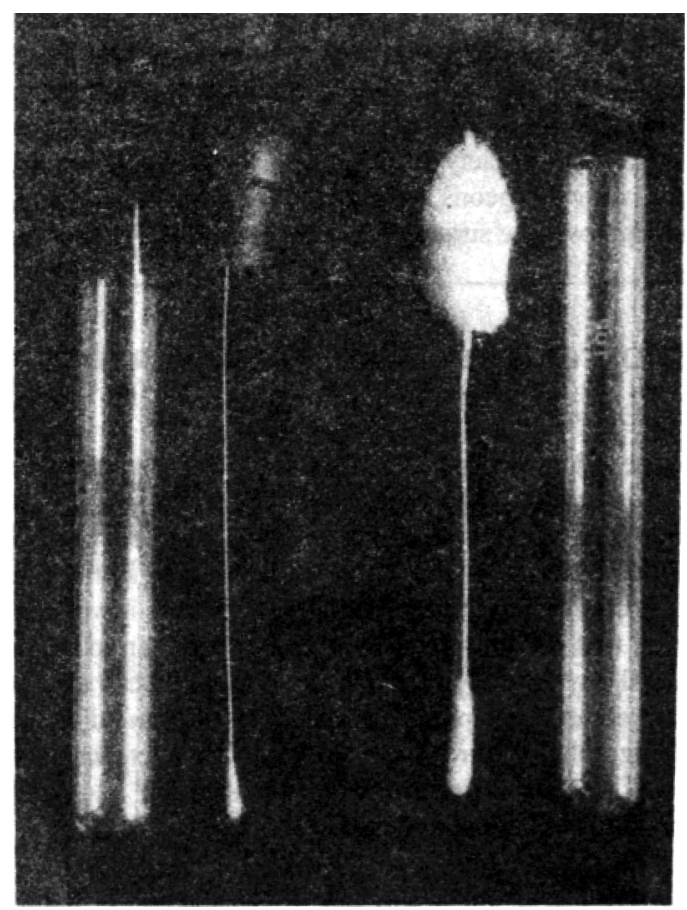

Fig. 1: The new aural swab on the left compared with the older variety on the right. 
The following observations were made :

Sampling: The conventional swab could not be passed through most external auditory meati and at times even through the widest ear speculum. It was found useful only in patients with wide external auditory meati or in mastoid cavities with wide meatoplasty. The newly fabricated swab could be used in all situation including narrow external auditory meati, and samples were taken through the sterile ear speculum.

Accuracy: With the newly fabricated swab a positive isolation and culture was obtained in 85 per cent of cases versus $\mathbf{5 8}$ per cent with the conventional swab. No contaminants were grown in the samples obtained with the new swab whereas 20 per cent of samples with the conventional swab grew contaminants.

Following this pilot study, all sampling from cases of chronic otitis media in our department is performed only with the new swab with consistently accurate results. Antimicrobial therapy depends on the isolation of the infecting organism and assessing its sensitivity. To achieve this accurate sampling of pus/blood/discharge without contamination and quick transportation of the laboratory are essential. This has been achieved with the newly fabricated aural swab. Moreover, the swab is simple to fabricate, robust, reusable and cheap (Rs $2 /$ - per swab). It can be used by any medical or paramedical person with minimal training.

\author{
Lt Col A RAVI KUMAR", Mr E VEERAJI ${ }^{+}$ \\ Associate Professor \\ Dept of ENT, \\ ${ }^{+}$Medical Cadet, \\ Armed Forces Medical College, \\ Pune 411040
}

\section{REFERENCES}

1. Finegold SM, Martin WJ. editors. Diagnostic Microbiology, Gth ed. St Louis: Mosby, 1982.

2. Rubin SJ. Specimen collection and processing. In: Howard BJ, Klan JH, Dubin SJ, et al, editors. Clinical and pathogenic microbiology. St. Louis: Mosby, 1987.

3. Baron EJ, Peterson LR, Finegold SM, editors. Diagnostic microbiology, 9th ed. 1994. St. Louis: Mosby 1994; 53-64.

4. Howard BJ, et al. Clinical and pathogenic microbiology, 2nd ed. St. Louis: Mosby, 1993; 227-8.

\section{SCREENING OF BLOOD TRANSFUSION - AN EARLY EXPERIENCE}

\section{Dear Editor,}

We wish to share our experience with respect to blood units found unfit for use following laboratory tests over a period of $31 / 2$ years in an active blood bank of a 598-bedded hospital.

On an average, over 100 donors were bled every year. Ninety nine per cent of the donors were service personnel. After blood donation samples were promptly tested for VDRL, HbsAg and HIV 1 and 2. The VDRL was tested using Rapid Plasma Reagin (RPR) test, HbsAg by Reverse Passive Haemagglutination (RPHA) and HIV 1 and 2 by the HIV Tridot test kit. On an average. 0.8 per cent of the blood units were found to be unfit for use due to a positive test for one or more of these diseases. These findings correlate well with those obtained from other centres in India [1]. Some donors gave positive result for more than one test (Table).

It will be well appreciated that the individuals harbouring the disease were asymptomatic and so remained a potential source for the spread of the disease to others. It is likely that the incidence of these disease will increase in future [2]. All blood banks must therefort stringently test blood as per the Govemment directives. This is not only a legal requirement, but as this limited data shows, it is ethically mandatory.

Lt Col haRSH KUMAR*, Maj MS BHINDRA ${ }^{*}$

"Classified Specialist (Pathology)

166 Military Hospital

C/o 56 APO

${ }^{+}$Classified Specialist (Pathology)

92 Base Hospital

$\mathrm{Cl} / 56 \mathrm{APO}$

\section{REFERENCES}

1. Nandi J, Bhawalkar V., Mody H, Elavia A, Desia PK, Banerjec K. Detection of HIV-1, HBV and HCV antibodies in blood donors from Surat, westem India. Vox Sang 1994; 67: 406-7.

2. Lackritz EM, Satten GA, Aberle-Grasse J. Estimated risk of transmission of the human immunodeficiency vinis by screening blood in the United Stales. New Engl J Med 1995: 333: $1721-5$. 